\title{
Multidisciplinary models and guidelines for eProcurement projects: the eReadiness phase
}

\author{
C. Batini, F Cabitza, G. Cammarota, D. Ciriaci, M. Corsi, A. Maurino, R.
} Russo, S. Scipioni. M. Telaro

DISCO, Università di Milano Bicocca \{batini,cabitza,maurino,telaro\}@disco.unimib.it

LUISS Guido Carli Roma

\{gcammarota,mcorsi,dciriaci\} @luiss.it

DIS, Università di Roma "La Sapienza"

\{ruggero.russo,sirio.scipioni\} @dis.uniroma1.it

\begin{abstract}
This paper presents a multidisciplinary methodology for developing public eProcurement (eProc.) projects in countries whose economy are either emerging, developing or in transition. The focus is on the first part of the methodology, namely eReadiness. Our aim is to bring out a number of issues, which are currently challenging many eGovernment projects through an integrated approach by encompassing sociological, economic, organizational, legal and technological factors.
\end{abstract}

\section{Introduction}

eProcurement (eProc.) has been considered as a relevant area in eGovernment since the Green Paper issued by European Union [1] and has been confirmed in the strategy defined at the Lisbon EU summit in 2000 and in the 2005 action plan [3]. A number of directives have been outlined concerning eProc. Due to the interdisciplinary nature of the area, goals and objectives for eProc. pertain to a wide range of research issues, i.e. social, economic, organizational, juridical, and technological research issues. In Figure 1 the inter-relationships among such issues are outlined, as compared with the traditional "technology centred" approach. 


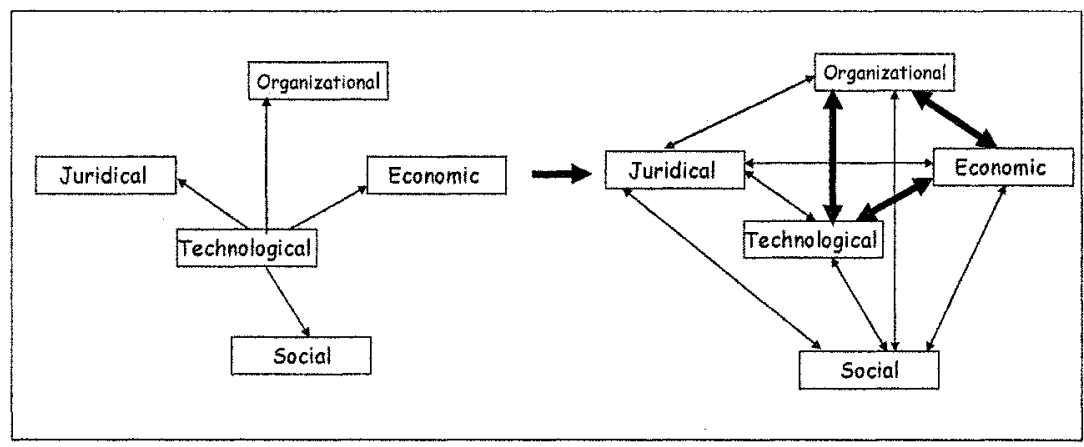

Fig. 1. The technology centered vision and the multidisciplinary one

Concerning first the specific areas:

- Sociological issues provide an improved understanding of the interactions between citizens and users at large, the business sector and public administration, and prevent or buffer possible conflicts between the uses of different modes of interaction and the various established cultures.

- Economic and organizational researches provide predictions and evaluation of impact of the effects of eGovernment projects on economic growth. Furthermore, they allow identifying the implications of socio-technical processes and effects for citizens, businesses and institutions.

- Juridical aspects are crucial in every project involving Public Administrations (PAs), since the organization of PA and the administrative processes are deeply influenced by the general legal framework and by the specific laws and rules enacted for the new initiatives to be undertaken.

This paper presents guidelines to steer the sustainable and effective development of eProcurement systems for the PA, especially in the context of the Mediterranean area, by using a multidisciplinary approach, considering the social, economic, organizational, legal, technological dimensions. For the sake of brevity we focus mainly on the relationship among economic, organizational and technological issues; with regard to technologies, we are specifically concerned with service oriented computing and information management, which are usually seen as relevant issues in innovative eGovernment projects. Guidelines concern two macro-phases of the eProc. design activity, namely a. eReadiness, and b. Design of the eProcurement solution. In this paper, for reasons of space, we focus on the eReadiness macro-phase. The reader interested in the second macro-phase can refer to [2].

The paper is organized as follows. In Section 2 we present technological, economic, organizational eProc. models used in our guidelines; in Section 3 a short description of the whole methodology is provided. Section 4 focuses on the first sub-phase of the process, Context reconstruction; Section 5 describes the second phase, eReadiness, which provides the name to the whole macro-phase. Section 6 presents related works and, finally, Section 7 draws conclusion and future research. 


\section{2 eProcurement models}

According to the graph of influences introduced in Figure 1, the organizational structure of the eProc. process should be coherent with the technological infrastructure, and, at the same time, should be chosen considering mainly the impact of the eProc. process in the economy of the country. In order to show how technologies can become an enabling factor in eProc. projects, we (shortly) present the technological, organizational, and economic models adopted in our proposal.

In an eProc. system a new technological architecture is needed, to coordinate information exchanges among the information systems of the several companies and the Public Authorities involved in an eProc. process, trying, at the same time, to preserve the autonomy of each involved subject. The achievement of this target requires cooperation among the various administrations to develop the ICT process, also taking into account the constraints and the differences among organizations [4].

In the traditional client/server transactions (see Figure 2,a) if a citizen or a business receives a service whose supplying requires the interoperation of several PAs, it has to interact separately with the different PAs involved. This result is an increase of the time for the supply of the service and in its worse quality, for the absence of an automatic process managing the operations and for problems related to the fragmentation of responsibilities, possible interruptions of services inside each agency, and for the heterogeneity of their systems. In Figure 2.b a possible technological architecture proposed to implement the improved interaction is shown.

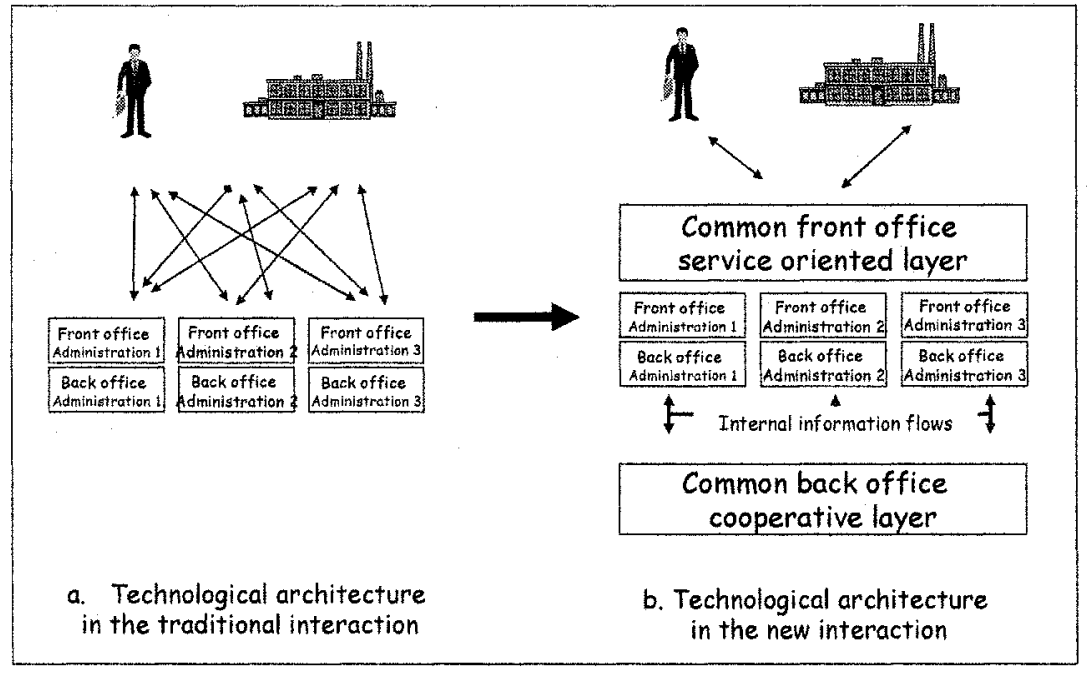

Fig. 2 Technological architectures for G2B, G2C relationships

The front-office layer allows a more efficient and automatic communication with the clients through the use of web based technologies (e.g. web portals), while the back office layer is introduced to improve the communication among the different cooperating organizations. Focusing on the back-office side, through the service 
oriented technologies [5], organizations implicated in a specific eProc. process can cooperate using common interfaces which allow the interoperable communication among them even if their internal systems are implemented with different technologies.

With regard to organizational issues, eProc. can be realized in different forms which are referable to two models, the Indirect Procurement System (IPS), and the Direct Procurement System (DPS). Such models can be described on the basis of two key-concepts: the Contracting unit, namely the public administration which purchases goods and services and bears the relative costs, and the Ordering subject, which manages the purchasing phase of the eProc. process.

In the IPS model, the Contracting unit makes the demand estimation, the budget definition and the need notification. The sourcing activity is handled by a different subject, which does not coincide with the Ordering subject. In the IPS model (for example, in Italy [6] and in Lebanon [7,8] the Ordering subject can be a corporate body, which can be either public or private. The other phases of the eProc. process are managed by the Contracting unit. Differently, in the DPS model (adopted, for example, in Morocco [9]), the Contracting unit coincides with the Ordering subject. Here the public administration which purchases good or services manages the purchasing procedure.

Regardless the eProc. model chosen, the use of ICT in the procurement process may lead to benefits; for example, the costs and time reductions for managing information, and the enhanced integration, comparability and quick update of data coming from different sources. Moreover, ICT investments can induce, as a direct effect, an increase in labour productivity (more capital per worker and reorganization of the back-office procedures) and as indirect effect, through the well-known accelerator/multiplier effect, GDP growth. Clearly, there exist economic and social barriers to the achievements of these targets, and the possibility of achieving them is correlated with the model of eProc. chosen by a government. In fact, the IPS model allows i) better inventory coordination and cost control, namely, economic rationality, ii) more simplification, due to the high procedural management uniformity, and iii) improved accountability, due to the reduced decision maker units and to standardized decision making. The IPS model may lead to less competitive markets because not every enterprise may be able to supply all the goods and services ordered by the central administration to cover all the needs identified. In particular, there may be a stronger loss of competition if both central and local public administrations are obliged to purchase through a single subject (as in the IPS). The DPS model, instead, allows the achievement of an high autonomy of the single administrations and enables the access of new suppliers, even of the smallest and local ones. However, the DPS induces a loss of control due to the improved number of decision maker units. Finally, among the barriers to the introduction of an eProc. system and to the achievement of the economic goals stressed above, there is the low level of economic development, the existence of poor private competitors services (as stressed before), and a low literacy level. 


\section{The guidelines at a glance}

Due to the many factors involved in the implementation of an eProc. system, in order to manage the complexity, we propose a set of guidelines which are drawn from a multidisciplinary corpus of models, lessons learned and best practices. As described in the introduction, two are the main macro-phases of an eProc. development project: eReadiness, and Design of the eProc. solution. The first macro-phase (see Figure 3, where inputs and outputs of the process are described) is in charge of collecting, organizing and evaluating the existing eProc. solution according to a multidisciplinary approach. The result of this macro-phase is a quali/quantitative evaluation of the actual system.

The second macro-phase is in charge of defining objectives, strategic and detail plans for the design (or re-design) and development of the eProc. system. Even in this macro-phase, multidisciplinary models and tools help the designer to understand and choose the best instruments to use in order to obtain an effective project. eReadiness includes the Context Reconstruction and Context Assessment phases while the Design of the eProc. solution includes the eProc. process reengineering and eProc. Design phases.

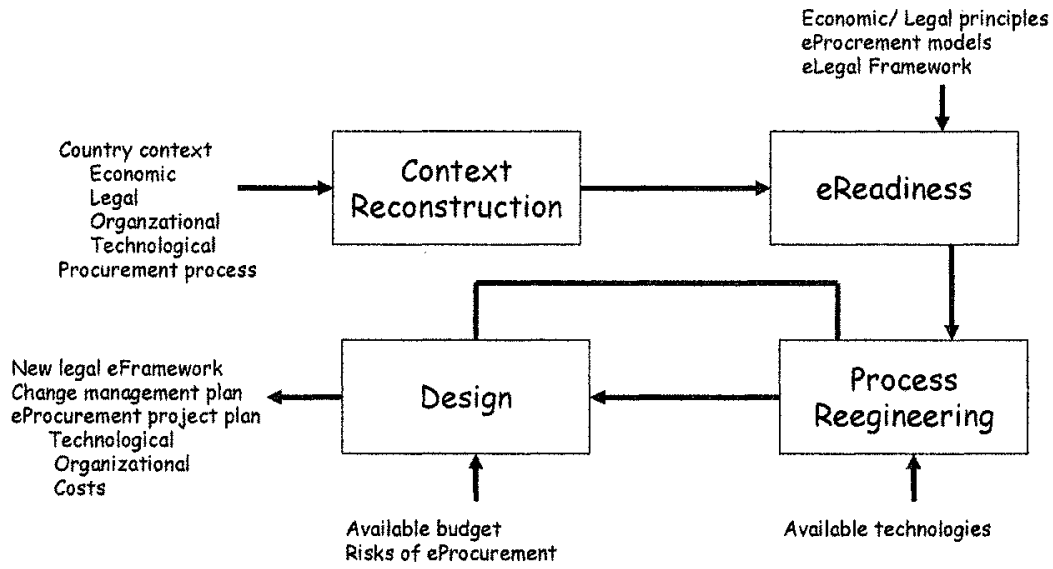

Fig. 3 Methodological framework for eProc. projects

The guidelines proposed in the following can be seen as a methodological framework within which the policy maker for an eProc. system in her country can find general directions and specific indications for the choice of the best path of intervention. 
phase

\section{Context Reconstruction}

The goal of the first phase is to provide a clear understanding of the organizationaleconomic-technological framework of public procurement of goods and services in the considered country and, more specifically, a more detailed picture for some good and service typologies aimed at detecting specific organizational networks of stakeholders.

This phase is performed through two different steps: Data collection, where a wide acquisition of knowledge is performed, and State reconstruction, where the relationships among the dimensions previously found are defined. In fact, each procurement activity, from demand estimation to accounting, involves several actors, which is both the organization units of the public administration, and the service and goods suppliers and any other juridical entity which has a share or an interest at any level in the overall procurement process. They can be seen as bound together by thick (social and organizational) networks of relationships; such relationships correlate the existing policies and practices to the roles and functions which apply them and to the (often implicit) interests which move their actions. Notice that this phase can be optionally skipped in the case in which the results of the phase are already available or the production of such data is too much expensive with respect to the global cost of the project.

In the Data collection step we gather data from heterogeneous sources; such data came from two different types of sources: primary or secondary sources. In the former case the data are directly acquired by the source; for example, the set of laws regulating the eProc. process can be taken by legal office of public administration. In the case of the latter source type the data was already elaborated by third part elements. For example, the GDP of a country can be acquired by the national statistical bureau. The choice of which type of data source to consider is related to a number of factors such as: cost for producing data, reliability of the data source, time needed to produce data. Examples of data which has to be collected for an eProc. project are:

- economic dimension: GDP, effect of eProc. cost with respect to the public budget;

- legal dimension: legal framework for eProc.;

- social dimension: corruption rate;

- organizational dimension; general organization chart of PA, most relevant procurement stakeholders, current workflow of procurement process;

- technological dimension: technologies used in PA.

In the State reconstruction step, correlations between the elements found in the previous analysis are found, according to the relationships presented in Figure 1. In particular we characterize the main organizational networks involved in the current procurement process and correlate: i) organizational units (organizational dimension), ii) the roles they cover in each procurement subprocess (legal), iii) the data sets they manage and use in the processes they are involved in (technological), iv) the ownership and accountability they have with respect to the different data sets (economic/ legal dimension), and v) the functions such data have in the subprocess (technological). 
Moreover, it is important to correlate procurement subprocesses with the rules regulating them, both general laws (e.g., state laws concerning privacy) and lower level rules (e.g., department procedures and business rules).

To organize such information and to explicit the above mentioned correlations, we propose to use tables as effective instruments. With regard to the correlations between technological dimension and the organizational one, we propose to conceive and populate some matrixes:

- an Actor/ Data set matrix, where each cell specifies whether an organizational unit either creates (i.e., owns) or just consumes (i.e., uses) a set of data such as good orders, contracts, tenders.

- a Process / Actor matrix, where each cell specifies whether an Actor either leads or participates in the procurement subprocesses (e.g. order collection, tendering, contracting) and hence assigns the responsibilities for the digitization activities proposed in the following methodological phases.

- a Process / Data set matrix, where each cell represents the relationship, in terms of inputs and outputs, between information and internal processes which use and possibly transform it according to organizational requirements.

- an Actor / Technology matrix describing technologies presently used by each organization involved in the eProc. process. Such a matrix will be used to make an evaluation of the technological advance of the organizations involved, in order to plan effectively the most suitable modules for the overall architecture. The presence of legacy systems, for example, requires the implementation of suitable wrappers to support the communication among the different organizations.

In Table 1 we report an example of Actor/Data set matrix, applied to the Italian Procurement system. The Chambers of Commerce provides the complete list of business actors (the Business registry) to the ordering subject, which publishes a Request for Quotations about the tender to suppliers.

Table 6 Example of the Actor/Data set matrix

\begin{tabular}{|l|l|l|l|}
\hline Actors/ Data Sets & $\begin{array}{l}\text { Business } \\
\text { registry }\end{array}$ & RFQs & $\begin{array}{l}\text { Product } \\
\text { quotations }\end{array}$ \\
\hline Ordering Subject & Uses & Creates & Uses \\
\hline Suppliers & & Uses & Creates \\
\hline $\begin{array}{l}\text { Chambers of } \\
\text { Commerce }\end{array}$ & Creates & & \\
\hline
\end{tabular}

\section{5 eReadiness}

eReadiness refers to the extent an organizational and social network is ready to accept the ICT enabled innovation of processes it is involved in and, above all, how ready it is to take advantage from digitization. This phase determines how existing policies and practices and the institutional framework favor the implementation of a sustainable eProc. system. In order to get such an evaluation, the phase encompasses: i) a 
qualitative assessment aiming at identifying the main problems and the corresponding critical areas, i.e., both the processes (or activities) and the related networks of the stakeholders, users and customers of those processes, and ii) a quantitative assessment identifying a reliable measurement of the main factors to base the following phases on.

As regard eReadiness, a number of proposal exist to assess eReadiness at country level (see Section 6); we adapt them to provide a comprehensive and synthetic indicator of the extent an organizational unit (and the network of partners involved) is ready to gain the benefits offered by ICT in terms of policy, infrastructure and groundlevel initiatives.

With regard to qualitative aspects, the major problems related with the procurement services are detected by involving the key stakeholders of the current procurement process through interviews, questionnaires and participative observations. For example, assume that questionnaires return these problems: (1) requests for quotations take a long time to reach suppliers (and so replies); (2) some requests are lost or misdelivered; (3) prices are still too high. These are quite heterogeneous in scope and nature and relate to different critical areas. Notwithstanding that, those indications give us precious elements to identify problems to involved areas so as to identify critical areas and correlated processes and stakeholders. The problems reported by users can be related, respectively, to the use of regular mail, to incomplete/inaccurate address data and to the awarding process (e.g., sealed bid vs reverse auction).

Quantitative analysis takes into account finding the most relevant indicators to measure and then assigning them correct values according to the state reconstruction phase. In the following we focus on economic and technological issues, providing several examples of indicators.

In our view, an $\mathrm{eReadiness}$ assessment with reference to socio-economic indicators should assess first the macroeconomic environment and the availability of ICT capacity and training (literacy level, enrolment in secondary and tertiary education institutions, $\%$ of schools equipped with computers, \% of internet-connected computers of university students, number of IT specialists, engineers and programmers, number of managers and officers). Such information is important in order to evaluate whether there exist the general economic and legal preconditions for implementing an eGovernment system.

Secondly, it should focus on the legal/regulatory environment (interconnectivity and interoperability, use of systems of advanced electronic signature, use of systems of certified e-mail, use of secure electronic payment systems), it should evaluate the diffusion of ICT use in business and in the public administrations involved, and its affordability. That is to say, the access to and use of ICT among businesses (\% of companies which have at least one computer; $\%$ of companies with internet access), the local businesses with websites (\% of companies which have a web presence), the use of ICT by small and medium-sized enterprise (\% of SMEs using ICT for procurement), the level of eCommerce (\% of growth of eCommerce; \% of firms selling products online). At the same time, to evaluate the "internal" impact of eProc. and whether an administration is eReady or not to implement and use an eProc. system, the assessment should evaluate the skill level of the public servants, the diffusion of computers in public administration, (\% of connected computers in the PAs involved, number of IT 
specialists, engineers, managers and officers). Furthermore, it should assess the communication costs (cost of telephone services, cost of mobile phone), the cost of internet access and use (ISP and telephone use charge, price of modems, price of PCs), the mobile phone penetration, the organizational costs (costs of consultancy and training in Public Sector), the cost of Public Sector staff (average salary), the cost of hardware and software (amount of public sector investments in hardware and software) and the total amount of procurement. Such information is important to evaluate whether eProc. may act as an enabler of ICT diffusion in private business, to evaluate the potential impact of eCommerce on competition among firms (in particular on SMEs), and to evaluate the cost of investments in training, hardware, software etc. needed to implement it.

Technological issues concern, in our approach, the area of cooperative architectures, including service oriented computing, and the area of information quality. With reference to architectures, examples of indicators concern:

1. the diffusion and obsolescence of legacy systems in PAs and private enterprises. Such information is important as it influences the strategy for the development of the architecture (use of wrappers or redevelopment of the information systems of the organizations);

2. the diffusion of middleware software (e.g. message queues, Service oriented computing, remote method invocation) to interconnect servers, measured e.g., through the $\%$ of servers connected to a middleware.

With reference to information quality, indicators concern:

1. the presence in the information processing activity of control activities, which guarantee a better level of accuracy in data;

2. the $\%$ of data exchanged in electronic format, that do not have to be imputed with error prone procedures;

3. the level of currency in updates, that guarantees usage of the last copy of data;

4. the completeness of data in representing phenomena of interest, e.g., the completeness of registries of businesses involved in tenders;

5. costs due to low quality, critical areas and administrative processes responsible of low quality.

From the matrixes proposed in Section 4 , we identify relevant information quality dimensions and metrics for each data set and flow, and measure them so that critical areas can be identified to focus on in the reengineering phase. For instance, we can detect that the business registry is updated every three months and errors in updated data have an average rate of $3 \%$; consequently, accuracy and completeness of the business registry is, respectively, $97 \%$ and $95 \%$.

At the end of this step we may calculate an eReadiness Global Index, plus a set of recommendations to be considered in the design phase. E.g., the low number of IT specialists and officers may lead to outsource system development and management, while a learning plan can be set up for managers to avoid the externalization of strategies. 


\section{Related work}

The literature on eProc. [13] recognizes the necessity of an integrated effort of bringing knowledge related activities together, because public procurement is an extremely complicated function of government and requires interdisciplinary skills and knowledge including economics, political sciences, public administration, accounting, marketing, law, and engineering. Among the examples of critical issues for the successful implementation of any IT-system, Kawalek et al. [14] stress the importance of top management support, organizational adaptation, and training of employees. Besides, Oliveira and Amorin [15] consider an extra set of factors such as financial risk, risk of building a portal, and legislative issues necessary for the implementation of an eProc. system. In fact, procurement is a bilateral process, and the issue of whether public eProc. is adopted depends on the technological capabilities of public institutions and their willingness to adopt the system: whether efficiency gains are realized depends on whether potential adaptors are willing to sacrifice political independency for an increase in the overall public procurement system [16] However, the public procurement system's ability to accomplish goals or policies is influenced by its environment and, at the same time, influences its environment [13]

Our approach tends to stress that the use of ICT in a procurement process may lead to increased productivity of labour in the public sector because it results in a reorganization of the back-office procedures. If an effective relationship between ICTs and economic growth exists, it can be reasonable to wonder which are the preconditions which make it ready, and whether a country is more or less ready to benefit from it.

The main e-Readiness assessment tools comparison reports $[10,11,17]$ basically categorize e-Readiness tools with respect to what they measure and how they do it. eReadiness assessment tools and models can be divided into two main categories: those which measure readiness for business or economic growth (e-economy assessments) e.g., $[18,19]$, and those which focus on the broader possibility of the overall society to exploit ICT and benefit from it (e-society assessments), see [12,20].

As regards the measurement methodology, most of e-readiness assessment tools comparison reports categorize tools in: statistical or questionnaire based $[21,22]$ country case studies (e.g., the USAID ICT Assessment reports); interview and survey based third party reports [23].

In our view, an eReadiness assessment should support public decision makers' choice of how to introduce eProc., hence it has a strong practical and specific aim and it must predict impacts on i) the efficiency level, namely the economic return of the investment in eProc. on the involved public administrations, and ii) the effectiveness level, i.e. the gain in productivity of those public administrations involved in eProc. implementation with reference to traditional public procurement, and growth and private sector productivity.

With regard to technological issues, examples of methodologies for the choice of dimensions and measures and for the qualitative vs quantitative evaluation are proposed by Lee et al. [24], Kahn et al. [25] Pipino et al. [26], De Amicis et al. [27]. 
The distinctive aspect of our approach is to consider costs due to low quality, and relate them to administrative processes.

Several paradigms and technologies are proposed to cope with the problem of the development of distributed cooperative systems, the most important approaches are:

- service-oriented systems [28], based on the Web service technology which allows greater interoperability (through the service composition), and reuse of software and services;

- data integration in cooperative systems which allows to achieve the transparency of data with regard to the technological heterogeneity of the systems involved [29];

- intelligent agents systems, agent-based methodologies [30].

In our approach an original contribution is proposed with regard to the automatic and distributed orchestration of eProc. process among organizations. In the presented approach, in fact, orchestration is seen as a methodology to automatize the workflow of the cooperative process among organizations involved in eProc., thus simplifying the process and providing better and faster services for the private sector.

\section{Conclusions and future research}

In this paper we propose a set of methodological guidelines for the eReadiness phase, for building eProc. systems in public administrations. The key element of the methodology is its multidisciplinary approach that considers economic, organizational, technological issues and their relationships in the design of eProc. projects. We are now interested to practically apply the methodology in real life contexts. In fact, we are on the point to apply the whole process in public administrations of some countries such as Morocco and Lebanon. The experimentation will provide useful indications in order to better define the right balance among the theory and practical approaches.

\section{References}

1. European Commission, Public Procurement in the European Union: Exploring the Way Forward, Green Paper, (European Commission, Brussels, 1996).

2. C. Batini et al., Multidisciplinary Models and Guidelines for eProcurement Projects: the design phase, submitted to the eGovernment Conference, Brunel University, 2006.

3. IDABC, EU : European Commission publishes eProcurement Action Plan, eGovernment News (24 January 2005), hitp://europa.eu.int/idabc/en/document/3824/194, 2005.

4. C. Batini and M. Mecella: Enabling Italian eGovernment Through a Cooperative Architecture IEEE Computer 34(2), 40-45 (2001).

5. G. Alonso, F. Casati, H. Kuno and V. Machiraju, Web Services: Concepts, Architectures and Applications (Springer Verlag, Berlin, Heidelberg 2004). 
6. CONSIP, Quadro normativo CONSIP, www.consip.it/sc/pdf/QuadroNormativo.pdf (in italian) (CONSIP, Roma, last modified 27May 2005).

7. OECD, Good Governance for Development (GfD) in Arab Countries. $I^{\text {st }}$ Gigh Level Seminar on E-Procurement, 30-31 January, Naples, Italy. http://www.oecd.org/dataoecd/0/21/36266246.pdf

8. H. Makarem-Saab, E-Procurement: The Government of Lebanon Experience, in: Proceedings. of the Conference for Good Governance for Development in Arab Countries, Naples, Italy, January 2006, http://www.oecd.org/dataoecd/57/30/36238478.pdf.

9. H. Zakani and S. Sebbata, Morocco, in OECD, Good Governance for Development (GfD) in Arab Countries. $I^{\text {st }}$ Gigh Level Seminar on E-Procurement, $30-31$ January, Naples, Italy. http://www.oecd.org/dataoecd/0/21/36266246.pdf, pp. 16-17.

10. Bridges.org, E-Ready for What? E-Readiness in Developing Countries: Current Status and Prospects toward the Millennium Development Goals May 2005, (Bridges.org, Kampala, Uganda, 2005), http://www.bridges.org.

11. Bridges.org, E-Readiness Assessment: Who is doing what and where. Model 2001 updated February 2005, (Bridges.org, Kampala, Uganda, 2005), http://www.bridges.org.

12. CID, Readiness for the Networked World. A Guide for Developing Countries Information Technologies Group (ITG) (Center for International Development, Harvard University, Harvard, MA, 2000).

13. K. V. Thai, Public Procurement Re-Examined, Journal of Public Procurement 1(1), 9-50 (2001).

14. P. Kawalek, D. Wastell and M. Newman, Problematization and Obfuscation in eGovernment, in: Electronic Government, Second International Conference, EGOV 2003, Prague, Czech Republic, September 1-5, 2003, Proceedings. Lecture Notes in Computer Science volume 2739 , edited by R. Traunmuller (Springer, Berlin, Heidelberg, 2003), pp. 228-233.

15. L. M. S. Oliveira and P. P. Amorim, Public E-Procurement, International Financial Law Review 20(3), 43-47 (2001).

16. H. Z. Henriksen and V. Mahnke, E-Procurement Adoption in the Danish Public Sector, Scandinavian Journal of Information Systems 17(2), 85-106 (2005).

17. N. Choucri, V. Maugis, S. Madnick and M. Siegel, Global e-Readiness - for What? MIT Sloan School of Management, Paper 177, May 2003.

18. APEC, E-commerce Readiness Assessment Guide Asia Pacific Economic Cooperation (APEC, Singapure, 2000).

19. WITSA, International Survey of E-Commerce (World Information Technology and Services Alliance, Arlington. VA, 2000). 
20. CSPP, The CSPP Readiness guide for living in a networked world. A self assessment tool for communities (Computer Systems Policy Project, Washington, DC. 2000).

21. Bhatia, Sunil eASEAN-Readiness Assessment (IBM, Singapure, 23 November 2001), http://www.itu.int/asean2001/documents/pdf/Document-28.pdf.

22. McConnell International, Risk E-Business: Seizing the Opportunity of Global EReadiness, (World Information Technology and Services Alliance, Arlington. VA, August 2000), http://www.witsa.org/papers/e-readiness.pdf.

23. CIDCM Negotiating the Net (Center for International Development \& Conflict Management, University of Maryland, 2005), http://www.cidcm.umd.edu/papers.asp

24. Y. W. Lee, D. M. Strong, B. K. Kahn, R. Y. Wang. AIMQ: A Methodology for Information Quality Assessment, Information \& Management 40, 133-146 (2002).

25. B. K. Kahn, D. M. Strong, R. Y. Wang, Information quality benchmarks: product and service performance, Communications of the ACM 45(4), 184-192 (2002).

26. L. L. Pipino, Y. W. Lee and R. Y. Wang, Data quality assessment Communications of the $A C M, 45(4), 211-218$ (2002).

27. F. De Amicis and C. Batini, A methodology for Data Quality Assessment on Financial Data, Studies in Communication Sciences 4(2), 115-137 (2004).

28. M. Turner, D. Budgen and $\mathrm{P}$. Brereton, Turning a Software into a Service, IEEE Computer 36(10), 38-44 (October 2003).

29. D. Calvanese, G. de Giacomo. M. Lenzerini et al., Data integration in Data Warehousing, Journal of Cooperative Information Systems 10(3). 237-271 (2001).

30. M. Klusch, Intelligent Information Agents: Theory and Application, Journal of Cooperative Information Systems, 10(1/2), 51-56 (2001). 